\title{
Optimizing Domestic Water Consumption Using Fuzzy Logic
}

\author{
C.Veeramani ${ }^{1 *}$ Amrithaa $\mathrm{S} \mathrm{R}^{2}$ \\ \{veerasworld@yahoo.com ${ }^{1}$, amrithaasb16@gmail.com ${ }^{2}$ \} \\ ${ }^{1}$ Assistant Professor, Department of Applied Science (Mathematics), PSG college of Technology, \\ Coimbatore, India, ${ }^{2}$ BSc Student, Department of Applied Science PSG college of Technology, \\ Coimbatore, India
}

\begin{abstract}
This paper deal with the consumption of water in the household with different parameters in a house like a bathroom, kitchen, and laundry, and soon in fuzzy interface system for the result from the result we get two outputs that are actual consumption and reduced consumption. The advantage of using this article helps in water consumption as nowadays there are water crises everywhere, this logic provides us sufficient amount of water for our daily life.
\end{abstract}

Keywords: Water, Consumption, Fuzzy Logic.

\section{Introduction}

The explosive growth of a developing world has led to a significant increase in water requirements. A sufficient amount of water is not received by a sample of individuals due to unequal distribution of water. Water is another basic requirement for all living creatures on the planet, as per myth [5,6]. The amount of water available for domestic use has been steadily increased in recent years. It is our responsibility to conserve and use available water as efficiently and effectively in order to have enough water for future generations. The use of water in any form for any reason is associated with water consumption. While most people think of water supply seems like the only way to consume. Understanding how freshwater is consumed is essential, as many geographic places throughout the world constantly suffering from water crises $[9,10]$. All interior and outdoor uses of quality water are classified as residential water consumption (domestic use, household use, or tap water usage). Flushing toilets, cleaning clothes and dishes, showering and bathing, drinking, and so on are examples. Some of these consumptions can be detected, enabling us to compute the overall water consumed.

The major goal of this paper would be to reduce water consumption with fuzzy logic, which is focused on the process of reducing household water use. Prof. L. A. Zadeh [11] proposed the concept of a fuzzy set in 1965, based on a classical set, which laid the foundation for fuzzy sets. The phrase "fuzzy sets" refers to an extension of "classical notation set". The fuzzy set is comparable to the Boolean logic's superset, but with additional membership functions in the voids between true and false. The truth value of variables in fuzzy logic can be any real number between 0 and 1 , making it a sort of many-valued logic $[1,2]$. The process of assigning a system's numerical input to fuzzy sets with varying membership degrees is 
known as fuzzification. A membership function (MF) estimates how an input belongs to a set. The term "degree of membership" refers to the number of people who joined the group This value is usually confined to between 0 and 1 as the output of a membership function. This Membership level can be anywhere between 0 and 1. If it's 0 , the value doesn't belong in the fuzzy set, and if it's 1, the value does. Any number between 0 and 1 indicates how certain the value is that it belongs in the set. Also referred to as a membership grade or membership value. In the fuzzy logic system (FLS), membership functions are applied in the fuzzification and defuzzification processes to transfer non-fuzzy input data to fuzzy linguistic concepts and vice versa [3].

In a fuzzy interface system, membership functions such as triangular, trapezoidal, Gaussian, and piecewise linear exist [7,8]. The triangle membership function is being used in this case. This paper explains domestic water consumption with a various parameters like kitchen, bathroom, laundry, toilet, and shower and results about how the water consumption previously and after reduction. For this process there will be set of rules should be constructed.

The main objective of this paper is to quantify how much water we consume on a daily basis. The parameter from the household are kitchen, laundry, bathroom, toilet, shower and the aim of the project is consumption and reduced consumption. This method helps to improve water conservation efficiency. The data have been collected from the three different households, the parameters are kitchen, laundry, bathroom, toilet, shower, and the result is all about consumption and reduced consumption. The inputs are from the kitchen, laundry, bathroom, toilet, shower, and the outputs are consumption and reduced consumption (Re consumption) of water. The water consumption reduction is the rule base where rules are formed. The reconsumption describes the sufficient flow of water and it helps in saving water. The water in the different parameters is classified as low, medium, high, or sometimes very high according to the use of water. There are different membership functions in the fuzzy interface system here we are constructing the logic using the triangular membership function.

\section{Problem Discussion}

The data like "Actual flow scenario" and "Low flow scenario" are collected. The "low flow device" is used in order to calculate the amount of water that could potentially be conserved, the actual flow of water leads to wastage more water. The amount of water is measured using gallons. The actual flow of water tells about the consumption of water consumed in a week, which is given in table 1. The low flow tells about the reduced consumption of water in the fuzzy logic system, which is given in table 2. 


\begin{tabular}{|l|l|l|l|l|l|l|l|l|}
\hline S.no & Household & Monday & Tuesday & Wednesday & Thursday & Friday & Saturday & Sunday \\
\hline & & & & & & & & \\
\hline 1 & Kitchen & 9 & 7 & 21.41 & 11.71 & 5.9 & 19.71 & 4.7 \\
\hline & Bathroom & 4.2 & 4 & 5 & 4.8 & 4 & 4.5 & 3 \\
\hline & Laundry & 0 & 0 & 0 & 0 & 0 & 32 & 16 \\
\hline & Toilet & 8 & 12 & 10 & 12 & 4 & 14 & 6 \\
\hline & Shower & 23.73 & 50.43 & 41.53 & 54.88 & 43.01 & 32.63 & 62.29 \\
\hline & Total (day) & 44.93 & 73.43 & 77.49 & 83.39 & 56.91 & 102.84 & 91.99 \\
\hline & $\begin{array}{l}\text { Total (week) } \\
\text { 531 gallons }\end{array}$ & & & & & & & \\
\hline & & & & & & & & \\
\hline 2 & Kitchen & 23.44 & 8.05 & 15.26 & 4.107 & 6.77 & 0.98 & 16.1 \\
\hline & Bathroom & 8.62 & 5.03 & 5.77 & 2.03 & 1.51 & 1.98 & 0.94 \\
\hline & Laundry & 0 & 0 & 0 & 0 & 0 & 0 & 70 \\
\hline & Toilet & 14.4 & 17.6 & 14.4 & 14.4 & 17.6 & 11.2 & 8 \\
\hline & Shower & 21.12 & 39 & 50.45 & 60.75 & 42.38 & 52.91 & 39.25 \\
\hline & Total (day) & 67.58 & 69.68 & 85.88 & 81.29 & 68.26 & 67.02 & 134.29 \\
\hline & $\begin{array}{l}\text { Total (week) }= \\
\text { 574 gallons }\end{array}$ & & & & & & & \\
\hline & & & & & & & \\
\hline 3 & Kitchen Faucet & 10.56 & 51.745 & 5.895 & 2.2303 & 21.4125 & 4.8298 & 11.135 \\
\hline & Bathroom & 10.388 & 6.694 & 3.5292 & 6.815 & 4.4182 & 3.6725 & 10.3475 \\
\hline & Laundry & 28.23 & 31.43 & 0 & 0 & 48.8 & 37.56 & 94 \\
\hline & Toilet & 42.56 & 29.6 & 53.6 & 39.5 & 34.5 & 37.64 & 40.98 \\
\hline & Shower & 78.46 & 75.38 & 72.89 & 68.49 & 80.71 & 121.23 & 88.59 \\
\hline & Total (day) & 170.198 & 194.546 & 135.914 & 117.035 & 189.841 & 204.932 & 245.053 \\
\hline & $\begin{array}{l}\text { Total(week) } \\
1257.5149 \\
\text { gallons }\end{array}$ & & & & & & & \\
\hline
\end{tabular}

Table 1: Actual flow

\begin{tabular}{|c|c|c|c|c|c|c|c|c|}
\hline S.00 & Household & Monday & Tuesday & Wednesday & Thursday & Friday & Saturday & Sunday \\
\hline \multirow[t]{7}{*}{1} & Kitchen Faucet & 82 & 6.4 & 195 & 106 & 59 & 536 & 427 \\
\hline & Bathroom & 3.82 & 3.64 & 4.55 & 4.36 & 3.64 & 4.09 & 2.73 \\
\hline & Laundry & 0 & 0 & 0 & 0 & 0 & 30 & 15 \\
\hline & Toilet & 3.2 & 4.8 & 4 & 4.8 & 1.6 & 5.6 & 2.4 \\
\hline & Shower & 23.73 & 50.43 & 41.53 & 54.88 & 43.01 & 32.63 & 62.29 \\
\hline & Total (day) & 38.95 & 65.27 & 69.58 & 74.64 & 54.15 & 77.68 & 86.69 \\
\hline & $\begin{array}{l}\text { Total(week)= } \\
466.52 \text { gallons }\end{array}$ & & & & & & & \\
\hline \multirow{7}{*}{2} & Kitabon Fou & 1056 & (200 & (1) & 185 & & & 725 \\
\hline & Bathroom & 3.79 & 2.215 & 2.54 & 1.05 & 0.67 & 0.415 & $\begin{array}{l}1.20 \\
0.42\end{array}$ \\
\hline & Laundry & 0 & 0 & 0 & 0 & 0 & 0 & 30 \\
\hline & Toilet & 7.2 & 8.8 & 7.2 & 7.2 & 8.8 & 5.6 & 4 \\
\hline & Shower & 21.12 & 39 & 50.45 & 60.75 & 42.38 & 52.91 & 39.25 \\
\hline & Total (day) & 42.67 & 53.64 & 67.07 & 70.54 & 54.9 & 59.8 & 80.92 \\
\hline & $\begin{array}{l}\text { Total }(\text { week })= \\
429.52 \text { gallons }\end{array}$ & & & & & & & \\
\hline & & & & & & & & \\
\hline \multirow[t]{7}{*}{3} & Kitchen Faucet & 8.06 & 39.5 & 4.5 & 1.7 & 16.35 & 3.68 & 8.5 \\
\hline & Bathroom & 8.07 & 4.23 & 2.51 & 5.3 & 3.21 & 2.71 & 7.06 \\
\hline & Laundry & 1.5 & 0.5 & 0 & 0 & 1 & 2.5 & 1 \\
\hline & Toilet & 18 & 17 & 17 & 23 & 18 & 20 & 23 \\
\hline & Shower & 50.26 & 64.64 & 69.72 & 57.89 & 63.12 & 56.63 & 61.45 \\
\hline & Total ( day) & 85.63 & 125.23 & 63.01 & 87 & 81.56 & 71.89 & 100.56 \\
\hline & $\begin{array}{l}\text { Total(week)= } \\
614.88 \text { gallons }\end{array}$ & & & & & & & \\
\hline
\end{tabular}

Table 2: low flow consumption 


\section{Fuzzy Logic Procedure}

In the water consumption reduction process, the input parameters are kitchen, laundry, shower, bathroom, and toilet and output parameters are consumption and reconsumption. The memberships are formed by actual flow scenarios and low flow scenarios. The input value in the fuzzy is operated by function either AND or OR and gives the crisp output of all membership functions. According to the member of the family, size differs the consumption varies. The fuzzy logic procedure is shown in Figure 1.

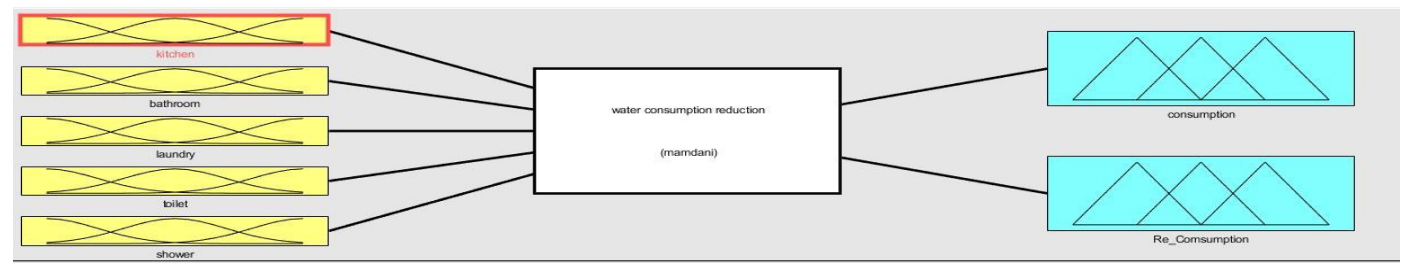

Figure 1: Water consumption reduction overview

\subsection{Input and Output Parameters}

In the kitchen, we use lots of water in washing vessels, vegetables, and dishwashers. We have differentiated the flow with the range of [starting value, maximum value, end value] for membership function as low, medium, high are [-3.17 0.509 12.1],[2.38 12.2122 .03$]$, [12.17 24 33.83] respectively as shown in Figure 2.

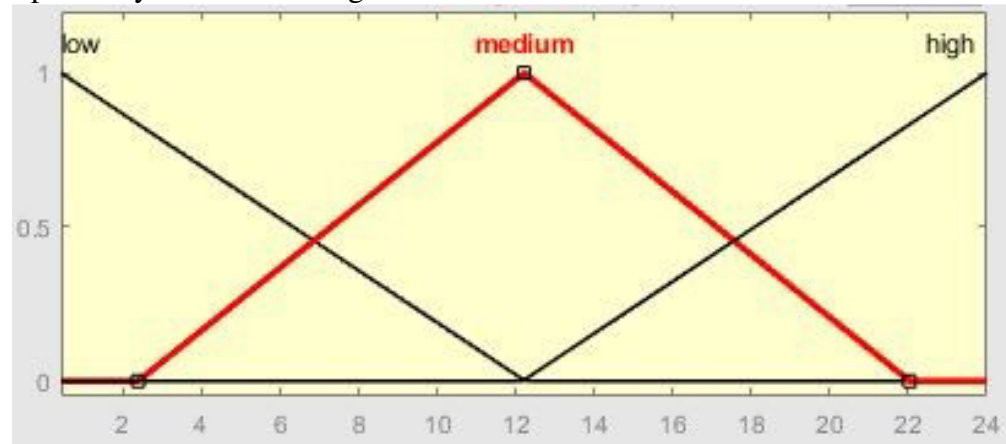

Figure 2: Membership function for water usage in Kitchen

In the laundry, we classify the membership function are less, normal, more for clothes regarding the amount of cloth, dirt, and type range are [-25 10 52], [17 52 87],[52 94 129] respectively, which is shown in Figure 3. 


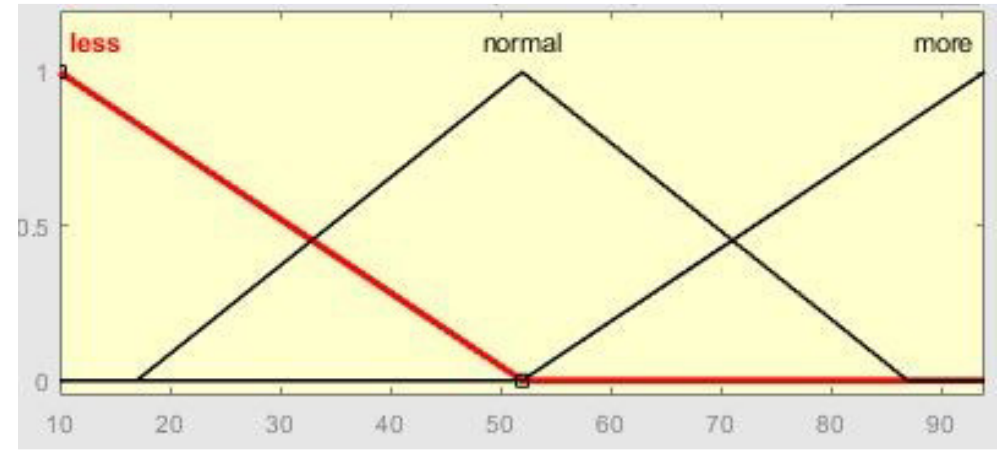

Figure 3: Membership function for water usage in Laundry

In the shower, the water consumption is a huge amount it consists of both hand shower and normal shower some- times bathtubs too. So it is up to 120 gallons, we have divided into four-parameter like low, medium, high, very high as [-12.33 21 54.33], [21 54.33 87.67], [54.33 87.67 121], [87.67 121 154.3] respectively, which is depicted in Figure 4.

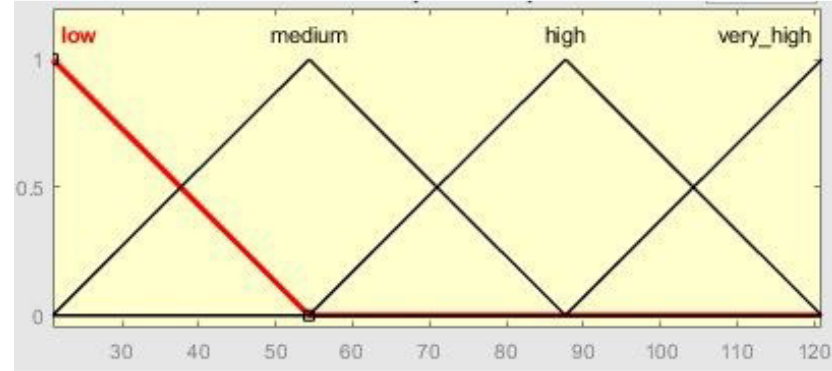

Figure 4: Membership function for water usage in Shower

In the bathroom, we consume lots of water for washing clothes, bathing in the bathtub, and cleaning. The parameters are dry, moist, wet as [-3.745 0.415 5.275], [1.247 5.408 9.568], [5.24 10.4 14.56] respectively, which is shown in Figure 5.

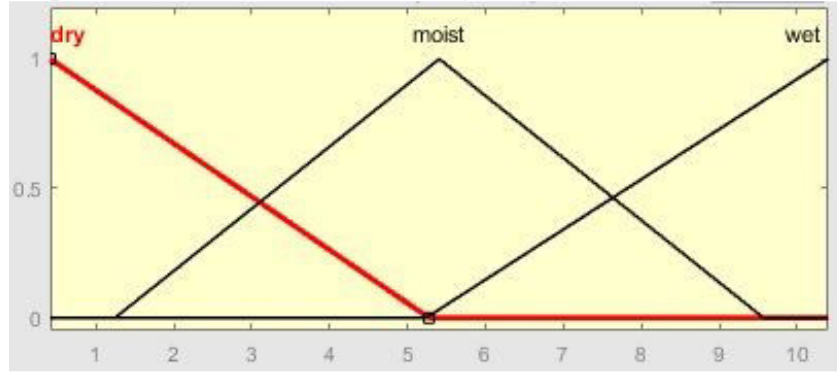

Figure 5: Membership function for water usage in Bathroom

The parameters are Low as [-15.87 1.6 19.07], Moderate as [1.6 19.07 36.53], High as

[19.07 36.53 54],Very high amount as water is [36.53 54 71.47]. The membership function of water usage in thetoilet is shown in Figure 6. 


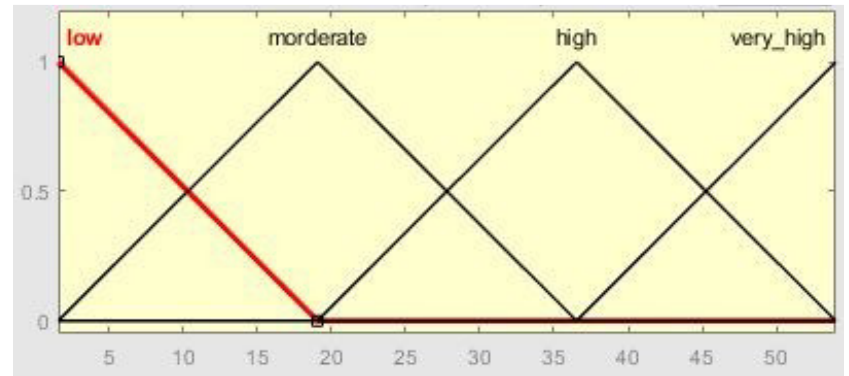

Figure 6: Membership function for water usage in Toilet

The consumption is calculated from the actual flow scenario table. As such Low - [-114.4 0 114.5], Normal - [0 114.5 229], High - [114.5 229 343.4], Very high - [229 343.4457 .8 ]. This membership function gives output1(Actual consumption)

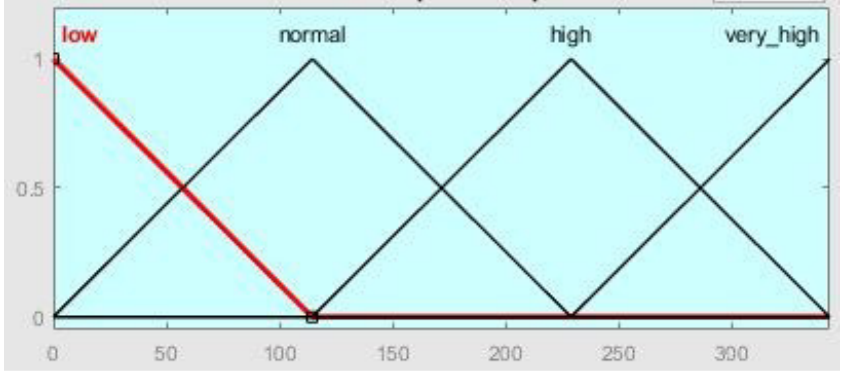

Figure 7: Membership function of actual water consumption

The consumption is calculated from the low flow scenario table.This Membership function for output2(reduced consumption)Low - [-85.32 0 85.32], Med - [0 85.32 170.7], High - [85.32 170.7 256], Very high - [170.7 256 341.2]

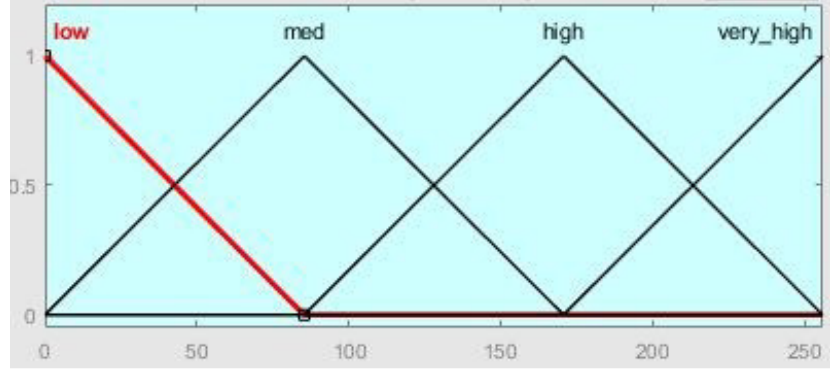

Figure 8: Membership function for reduced consumption

\subsection{Fuzzy Rule Construction}


The set of rules are formed by analyzing the actual flow chat and low flow chart. The rule base is developed, using expert knowledge of the effect of all the input variables used to develop the fuzzy system. The fuzzy rules are given in table 3 .

\begin{tabular}{|c|c|c|c|c|c|c|c|}
\hline S. No & Kitchen & Bathroom & Laundry & Toilet & Shower & OUTPUT 1 & OUTPUT 2 \\
\hline & & & & & & (Consumption) & (re consumption) \\
\hline 1 & Low & Dry & Less & Low & Low & Low & Low \\
\hline 2 & Low & Moist & Normal & Moderate & Medium & Normal & Medium \\
\hline 3 & Low & Moist & Normal & High & High & High & High \\
\hline 4 & Low & Wet & More & Very high & Very high & Very high & Very high \\
\hline 5 & medium & Dry & Less & Low & Low & Normal & Medium \\
\hline 6 & Medium & Moist & Normal & Moderate & Medium & Normal & Medium \\
\hline 7 & Medium & Moist & Normal & High & High & High & High \\
\hline 8 & medium & Wet & More & High & high & Very high & Very high \\
\hline 9 & High & Dry & Less & Low & Low & Normal & Medium \\
\hline 10 & High & Moist & Normal & Moderate & Medium & High & High \\
\hline 11 & High & Moist & Normal & High & Very high & High & High \\
\hline 12 & high & Wet & More & Very high & Very high & Very high & Very high \\
\hline
\end{tabular}

Table 3: Rules for fuzzy inference system

\section{Results and Discussions}

The result of the fuzzy inference system is implemented in the Mat lab fuzzy logic toolbox. The rules are extracted from the technical trading experts. In this, we can see the different values for the output as the input varies. According to the inputs, the result (i.e.) consumption and re consumption varies. The re consumption tells how minimum we can use the water for usage. The surface plot for bathroom vs kitchen is depicted in Figure 9. Further, the surface plot for the shower and toilet is shown in Figure 10.

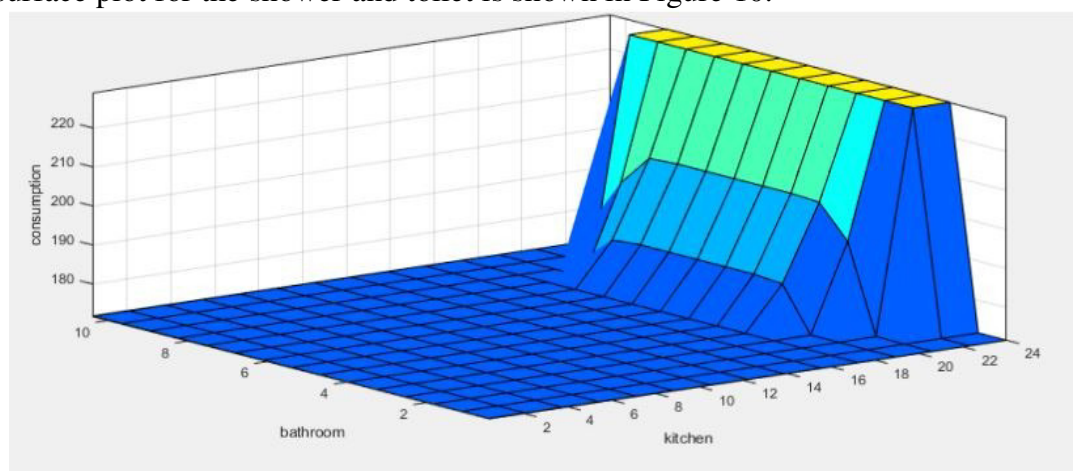


Figure 9: Surface plot for Bathroom vs Kitchen

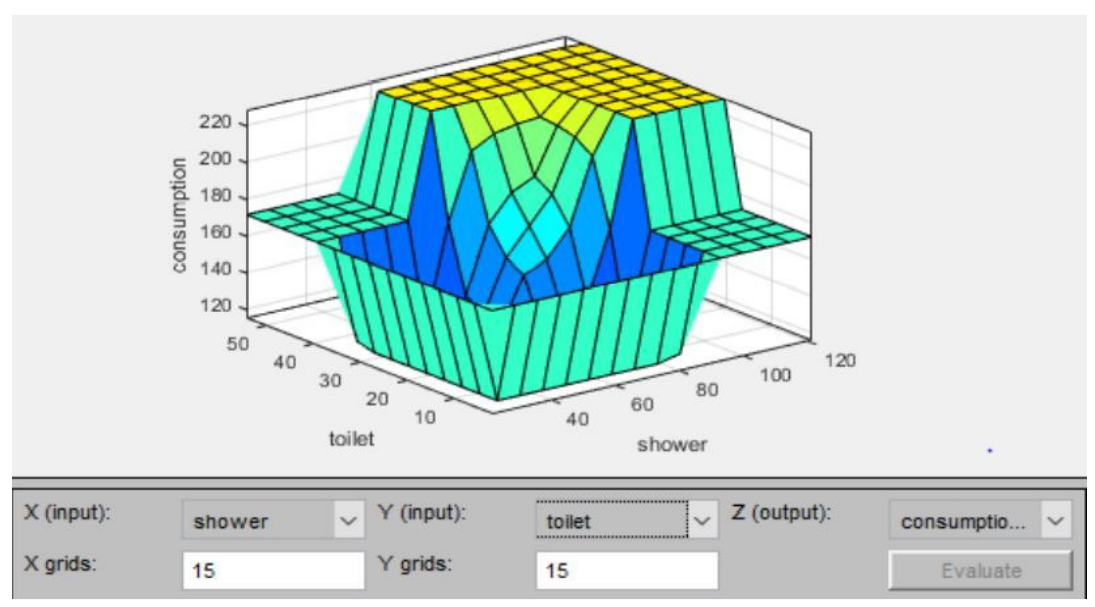

Figure 10: Surface plot for Shower and Toilet

The kitchen value and bathroom value are 14.3 and 6.83 lies between the max amount of medium flow and less amount of high flow respectively, Where the laundry value is 82.8 between less amount of medium flow and max amount of high flow. The toilet and shower values are 48.8 and 107 between high and very high flows. The input data can be entered according to get output required output. The inputs [14.3,6.83,82.8,48.8,107] and outputs [259,198], the consumption is 259 and Re consumption is 198 (reduced consumption).

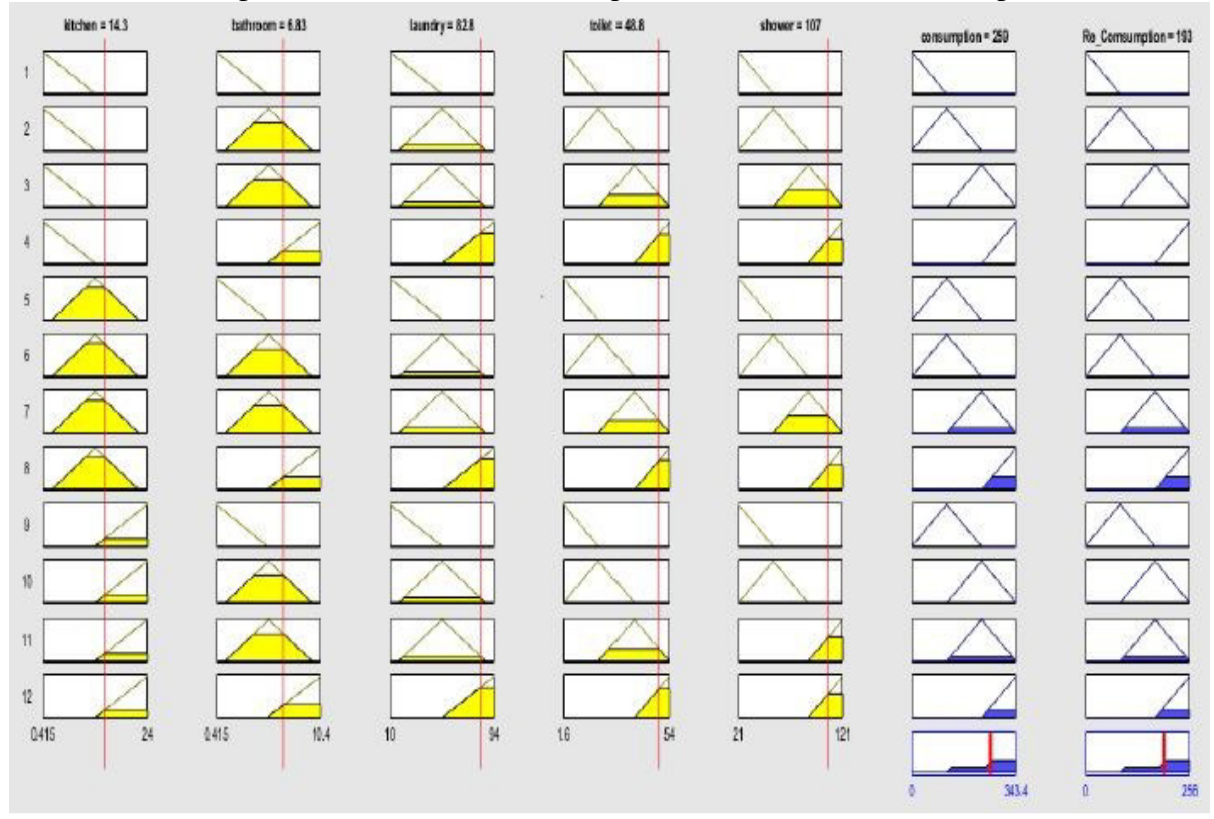


Figure 11:The Rule Viewer ofConsumption and reconsumption on [14.3, 6.83, 82.8, 48.8,

107]

The input values for kitchen, bathroom, laundry, toilet, shower are 8.04, 3.9, 38.6, 25.8, 35.2 respectively. And the outputs are $115,84.5$. The values of all the inputs represent that the flow is less medium than gives the respective output.
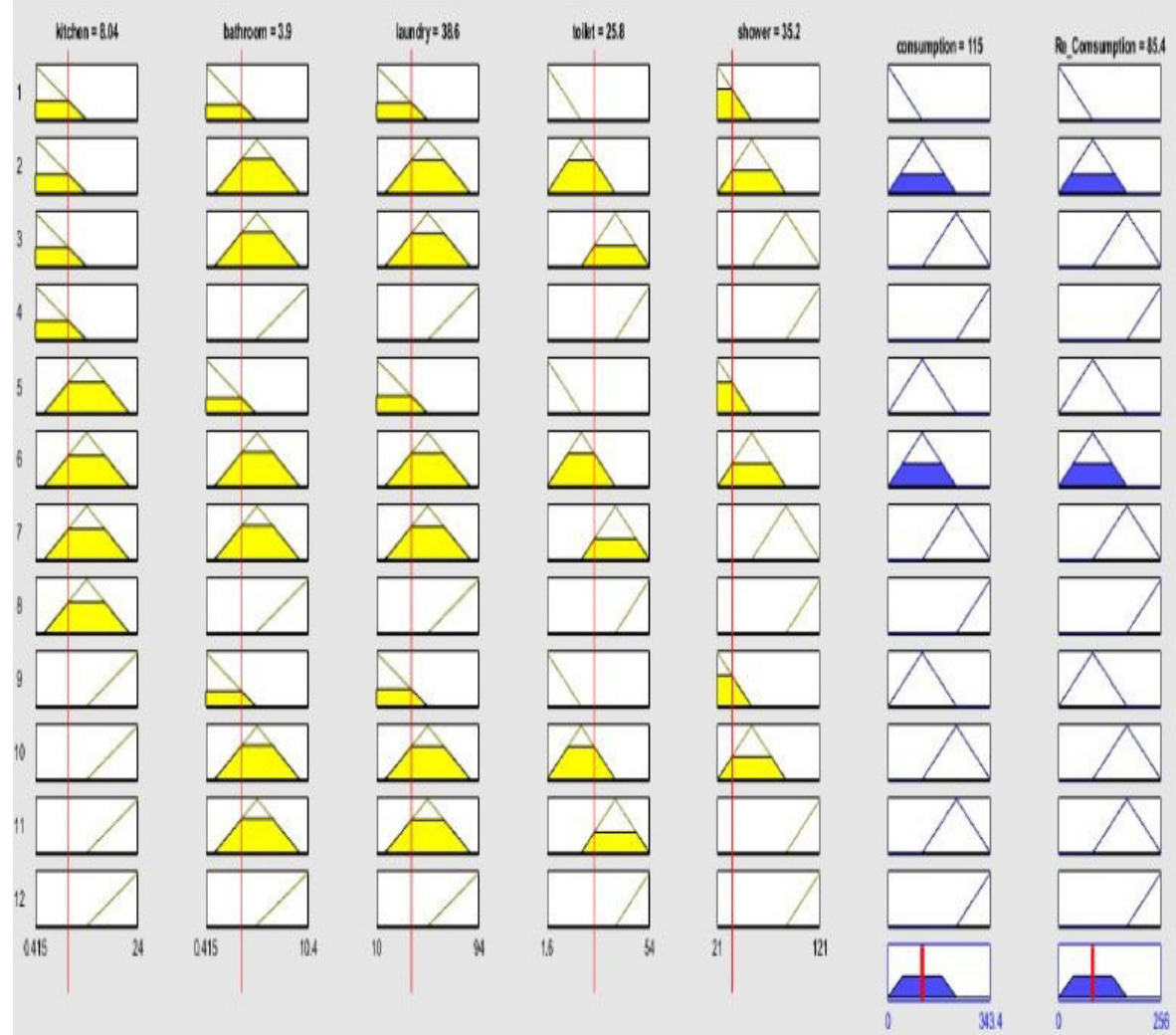

Figure 12:The Rule Viewer of Consumption and reconsumption on [8.04,3.9, 38.6, 25.8, 35.2

\section{Conclusion}

In this paper, we have observed from the different flows of water (i.e.) actual flow and normal flow, how the water can be used adequately. The rules have been formed in such a way as the output with daily water consumption and reduced amount of consumption it helps in saving water. In Developing countries, 70 percent of water is used for Agriculture, 22 percentage for Industry, and 8 percentage for Domestic purposes although there are considerable regional variations. Saving water is important for us and also for our future 
generations. Water is a precious resource, instead of waiting for somebody else to start conserving, let us as an individual, take the first step towards conserving water.

\section{Acknowledgement}

The authors would like to thank the management and principal, PSG College of Technology for generous support to carry out the project work

\section{References}

[1] G. J. Klir and B. Yuan, Fuzzy Sets, Fuzzy Logic, and Fuzzy Systems: Selected Papers by Lotfi A Zadeh. World Scientific, 1996,vol.6.

[2] R. Belohlavek, J. W. Dauben, and G. J. Klir, Fuzzy logic and mathematics: a historical perspective. Oxford UniversityPress, 2017.

[3] S. G. Milan, A. Roozbahani, and M. E. Banihabib, "Fuzzy optimization model and fuzzy inference system for conjunctive use of surface and groundwater resources," Journal of hydrology, vol. 566, pp. 421-434, 2018.

[4] S. M. S. S, D. S. Vijayan, M. Anand, M. Ajona, and T. Jarin, " Biodegradation of P-nitro phenol using a novel bacterium Achromobacter denitrifacians isolated from industrial effluent water ," Water Sci. Technol., vol. 00, no. 0, pp. 1-12, 2021, doi: 10.2166/wst.2021.354

[5] S. Koop, A. Van Dorssen, and S. Brouwer, "Enhancing domestic water conservation behaviour: A review of empirical studies on influencing tactics," Journal of environmental management, vol. 247, pp. 867-876, 2019.

[6] J. Li, S. Song, Y. Kang, H. Wang, and X. Wang, "Prediction of urban domestic water consumption considering uncertainty," Journal of Water Resources Planning and Management, vol. 147, no. 3, p. $05020028,2021$.

[7] H.J. Zimmermann, Fuzzy set theory and its applications. Springer Science \& Business Media, 2011.

[8] N. G. Seresht and A. R. Fayek, "Computational method for fuzzy arithmetic operations on triangular fuzzy numbers by extension principle,” International Journal of Approximate Reasoning, vol. 106, pp. 172-193, 2019.

[9] H. Rashid, S. B. Osman, N. Hassan, I. U. Ahmed, R. Das, and M. M. Karim, "A new design approach of home automation system for patients with physical disability to reduce water wastage and power consumption using renewable energy," in 2017 4th International Conference on Advances in Electrical Engineering (ICAEE). IEEE, 2017, pp. 770-774.

[10] O. Matsiyevska, P. Kapalo, J. Vrana, and C. Iacob, "Analysis of the water consumption in the apartment house case study," in International Scientific Conference EcoComfort and Current Issues of Civil Engineering. Springer, 2020, pp. 294-302.

[11] C. Nivetha, D. S. Vijayan, R. Ravishanker et al., Use of Pennywort for nitrogen and phosphate removal from sewage, Materials Today: Proceedings, https://doi.org/10.1016/j.matpr.2020.05.215 